\title{
CAUSAS E SOLUÇÕES PARA DESOBSTRUÇÃO DE EMISSORES NO MÉTODO DE IRRIGAÇÃO LOÇALIZADA
}

Nathalia Silva Barros ${ }^{1}$; Eletisanda das Neves ${ }^{2}$; Everton Valdomiro Pedroso Brum³ Tiago Baliero Cetrulo ${ }^{4}$

${ }^{1}$ Graduanda do Curso de Agronomia - UNEMAT - Câmpus Universitário de Nova Mutum, Nova Mutum, Mato Grosso, Brasil.

${ }^{2}$ Professora de Educação Superior/Departamento de Agronomia/Eng. Agrícola, UNEMAT - Câmpus Universitário de Nova Mutum, Nova Mutum, Mato Grosso, Brasil. eletisanda@unemat.br

${ }^{3}$ Professor de Educação Superior/Departamento de Agronomia/Eng. Agrônomo,

UNEMAT - Câmpus Universitário de Nova Mutum, Nova Mutum, Mato Grosso, Brasil.

${ }^{4}$ Professor de Educação Superior/Departamento de Agronomia/Eng. Agrônomo, UNEMAT - Câmpus Universitário de Nova Mutum, Nova Mutum, Mato Grosso, Brasil

\section{Recebido em: 15/05/2020 - Aprovado em: 15/06/2020 - Publicado em: 30/06/2020} DOI: 10.18677/EnciBio_2020B16

\begin{abstract}
RESUMO
A irrigação é uma prática agrícola utilizada para suprir a demanda hídrica das plantas em períodos não chuvosos. Essa técnica tem sido aprimorada ao longo dos séculos disponibilizando aos produtores diversos sistemas de irrigação, entre eles a irrigação localizada onde a água é direcionada próximo ao sistema radicular da cultura em horários e quantidades desejadas. Por outro lado, esse sistema apresenta alta suscetibilidade ao entupimento dos emissores ocasionado por natureza física, química, biológica e seu complexo, devido a qualidade da água. Partindo desse cenário, o objetivo do trabalho foi realizar um levantamento na literatura revisando estudos em torno da temática sobre as causas e possíveis tratamentos para desobstrução dos emissores, a fim de disponibilizar um documento reunindo várias experiências. Realizou-se uma busca nos portais do Google Acadêmico, Periódicos da Capes, Scielo e Revista Brasileira de Agricultura Irrigada, passando por critérios de inclusão e exclusão onde foram obtidos 22 artigos. Perante análise desses estudos constatou-se que o entupimento por natureza química foi o que apresentou maior frequência de relatos, seguido da natureza física e biológica. Referente aos tratamentos, a cloração apresentou maior porcentagem de utilização relatados nos artigos, seguido dos tratamentos com ácidos e filtros, ambos tratamentos proporcionaram resultados satisfatórios e insatisfatórios quanto a desobstrução.
\end{abstract}

PALAVRAS-CHAVE: Entupimento. Emissores. Qualidade da água. Tratamento 


\title{
CAUSES AND SOLUTIONS FOR CLEARING ISSUERS IN THE LOCATED IRRIGATION METHOD: LITERATURE REVIEW
}

\begin{abstract}
Irrigation is an agricultural practice used to supply the water demand of plants in nonrainy periods. This technique has been improved over the centuries, providing producers with various irrigation systems, including localized irrigation, where water is directed to the vicinity of the crop's root system, at desired times and quantities. On the other hand, this system has a high susceptibility to the clogging of emitters, caused by physical, chemical, biological nature and its complex, due to the quality of the water. Based on this scenario, the objective of this review was to carry out a survey in the literature, looking for studies around the theme, about the causes and possible treatments for clearing the emitters, in order to provide a document that brings together various experiences. A search was carried out on the Google Scholar portals, Capes Journals, Scielo and Revista Brasileira de Agricultura Irrigada, going through inclusion and exclusion criteria where 22 articles were obtained. In view of the analysis of these studies, it was found that clogging by chemical nature was the one with the highest frequency of reports, followed by physical and biological nature. Regarding treatments, chlorination showed a higher percentage of utilization reported in the articles, followed by treatments with acids and filters, both treatments provided satisfactory and unsatisfactory results regarding clearance.
\end{abstract}

KEYWORDS: Clogging. Treatment. Issuers. Water quality

\section{INTRODUÇÃO}

A água assim como sendo um recurso essencial a vida, do mesmo modo apresenta grande importância para uma agricultura de sucesso, sendo um dos principais fatores limitantes na produtividade por cumprir tarefas vitais no ciclo de vida de uma planta (FGV, 2016). Porém, em algumas regiões, por exemplo, o Centro Oeste, é afetada pela escassez da água em períodos específicos do ano, onde algumas culturas e safras somente se viabilizam mediante técnicas que visam suprir essa necessidade hídrica, entretanto, por outro lado comparado com o uso doméstico, industrial e outros a irrigação consome a maior parte de uso da água, exigindo cada vez mais meios que otimize a utilização da água de forma racional na agricultura irrigada (ANA, 2017).

Dentre os diversos sistemas de irrigação disponíveis atualmente, a irrigação localizada permite obter maior eficiência referente a otimização devido ao seu modelo de funcionamento (COELHO et al., 2017). O Censo Agropecuário de 2017 mostrou que a área irrigada que utilizaram o método de irrigação localizada por gotejamento eram de 1.038.720 hectares (IBGE, 2017) entretanto, os componentes que a constitui como exemplo, os emissores são facilmente susceptíveis ao entupimento (COELHO et al., 2017). A obstrução de emissores na irrigação localizada pode ser ocasionada pela presença de agentes físicos, químicos ou biológicos. Quando provocada por fatores físicos se deve a presença de partículas inorgânicas em suspensão (silte, areia, argila) e matéria orgânica (fragmento de plantas, resíduos animais, etc.) segundo Lima et al. (2018).

Os casos mais frequentes observados em relatos de estudos se caracterizam por agentes causais de origem biológica, como observação de mucilagem bacteriana e de algas nas tubulações provocando a obstrução, de origem química por utilização de águas com alto teor de ferro e outros compostos, de origem física causado por partículas de solo e restos vegetais. Além desses, Zocoler 
et al. (2015) destacam a qualidade de água, geometria dos orifícios, sistema de filtragem e sensibilidade do emissor à temperatura e variações de pressão. Carvalho et al. (2014) abordaram possíveis soluções de tratamento para o problema. Todavia, essas soluções ainda são lacunas, uma vez que as diferentes medidas a serem adotadas não são de conhecimento coletivo entre os produtores rurais, que frequentemente têm problemas com os gotejadores que compõem o sistema de irrigação, e que em certos casos realizam a substituição dos componentes de irrigação.

Tendo em vista esse episódio, o referido trabalho teve como objetivo realizar uma abordagem teórica sobre as causas da obstrução de tubulações dos sistemas de irrigação localizada e seus presumíveis tratamentos, revisando estudos realizados de caráter prático sobre a temática, com o intuito de reunir em um documento diversas experiências sobre o assunto, buscando simplificar o acesso da pesquisa.

\section{HISTÓRICO DA IRRIGAÇÃO}

O histórico em dados literários mostram que a irrigação foi uma das primeiras práticas de modificação do ambiente realizada pelo homem, as primeiras tentativas de irrigação eram bastante rudimentares, considerada uma técnica milenar que se entrelaça ao desenvolvimento e prosperidade econômica dos povos, porque muitas das civilizações antigas produziram em regiões áridas nas quais a produção só era possível graças à técnica conforme Portal do Meio Ambiente (2018) e dessa forma, grandes rios abasteciam a agricultura irrigada para as civilizações que se desenvolviam em suas proximidades, tais como o rio Nilo no Egito e a civilização da Mesopotâmia utilizando as águas do rio Tigre e Eufrates, por volta de 4000 A.C. entre outros.

As civilizações faziam a captação da água por meio de represas cercadas por diques, que conduziam a água por canais e comportas nas quantidades desejadas, um método bastante preciso para controlar a água no período chuvoso, e garantir o abastecimento na seca, onde chamados de período de vaca gorda e vaca magra. Sendo assim, essas pequenas práticas davam ao homem o domínio da ciência da irrigação, juntamente com o avanço tecnológico e a distribuição de informações sobre tal prática. Visto que a irrigação passou a ser utilizada em diversas partes do mundo, tornou-se importante o uso e manejo da água na agricultura moderna para garantia da produção suficiente e de boa qualidade (PORTAL DO MEIO AMBIENTE, 2018).

A irrigação no Brasil teve início no final do século XIX e começo do século XX nas lavouras de arroz do Rio Grande do Sul, se intensificando a partir da década de 1970 através expansão da agricultura em regiões com características climáticas menos favoráveis, e pelas vantagens observadas por essa prática. Iniciativas e apoios governamentais foram outros fatores que contribuíram para o incremento da agricultura irrigada no Brasil (ANA, 2017).

Segundo os dados do Censo Agropecuário, a área irrigada no território brasileiro atingiu em 2017 um total de 6.902.960 hectares (IBGE, 2017), realizando estudos sobre a expectativa futura de expansão de área da agricultura irrigada, o cenário tendencial para 2030 resulta em aproximadamente uma área total de 10,09 milhões de hectares irrigados no Brasil, cerca de 3,14 milhões de hectares incorporado, totalizando em média pouco mais de 200 mil hectare por ano, onde os sistemas de irrigação localizada e aspersão por pivô central serão responsáveis por cerca de $75 \%$ desse crescimento (ANA,2017). 


\section{USO E MANEJO DA IRRIGAÇÃO}

Em um projeto de irrigação é almejado o aumento da produtividade, economia de trabalho e água entre outros. Para se alcançar uma produção qualitativa e quantitativa maximizada a parte hídrica é um dos fatores limitantes apesar que o excesso da água no solo pode ocasionar efeitos indesejados, daí a importância de manejar a irrigação no momento certo e, em quantidades adequadas. Para eles a racionalização do manejo da água proveniente de irrigação proporciona benefícios como a minimização de gastos com energia e, ainda maximiza a eficiência do uso da água. Neste contexto, necessidade de irrigação decorre da distinção entre a demanda hídrica da cultura e a disponibilidade hídrica local. Esta diferença é quantidade de água irrigada. Porém, o manejo da irrigação deve-se ter cautela, como manter a quantidade de água no solo entre a capacidade de campo e o ponto de murcha permanente, de acordo com (MAIA, 2020).

Outro método para estabelecer um manejo racionalizado da irrigação segundo Maia (2020) é verificar a necessidade de irrigação que pode ser determinada a partir do balanço hídrico local, por meio do qual é possível determinar se haverá "déficit hídrico. Se o período de déficit coincidir com o período em que a cultura necessita mais de água, a irrigação pode resolver esse problema. Por outro lado, para haver uma eficiência no uso da água na agricultura irrigada por parte dos agricultores deve-se aumentar também a eficiência de aplicação, investindo em sistemas de irrigação mais eficazes e em tecnologias econômicas no uso da água.

\section{USO DE ÁGUAS RESIDUÁRIAS}

O uso das águas residuárias tem baixo custo quando comparada a de outras fontes não convencionais, mas o efluente deve ser tratado para a finalidade agrícola. Sendo assim, a irrigação com o uso dessa água pode complementar ou mesmo substituir temporariamente as chuvas durante períodos de seca, assegurando a produção agrícola (FREITAS, 2018). Esse material deve passar por uma metodologia de tratamento para que possa ser utilizado na produção, visto que esses efluentes possuem uma série de parâmetros com potencial causador de poluição dos recursos hídricos uma vez que depositado diretamente sem o devido tratamento, poderá desencadear uma significativa contaminação ambiental. Por outro lado, os efluentes de águas residuárias apresentam diversos nutrientes de grande valia na fertilização da produção agrícola, além disso, a irrigação deve optar por métodos que racionalize o uso de águas nobres (CARDOSO et al., 2015).

Um exemplo do uso desses efluentes são as águas residuárias da suinocultura. Juntamente com o avanço na criação de suínos, aumentou-se também a quantidade de dejetos gerado por esse setor, uma questão que acarreta problemas ambientais se não manejado e que carece de práticas para tal tratamento. Uma alternativa aceitável para os agricultores é a utilização dos dejetos como uso de fertilizantes, visto que esses materiais contem teores de matéria orgânica, ferro, nitrogênio, fosforo potássio entre outros elementos. Uma metodologia utilizada para realizar o manejo de dejetos são os processos que visem o armazenamento como as lagoas de decantação, onde interagem com ação bacteriana, e também atua na decantação dos resíduos e impurezas da matéria orgânica (CARDOSO et al., 2015).

Batista et al. (2014) relatam que na literatura existem diversos casos de trabalhadores rurais que foram contaminados com agentes patogênicos devido a manipulação das águas de reuso. O sistema de irrigação localizada se torna eficaz no uso de águas residuárias em virtude da aplicação do efluente com elevada 
eficiência diminuindo o risco de contaminação do produto comercial e de operadores em campo, entretanto as características da água dos efluentes apresentam fatores químicos, físicos e biológicos que quando combinados ocasionam a obstrução dos gotejadores operados com essas águas, já os microaspersores adquirem menor suscetibilidade a obstrução do que os gotejadores em virtude dos orifícios possuírem maiores diâmetros, porém são menos utilizados para aplicação de águas residuárias.

\section{QUALIDADE DA ÁGUA PARA IRRIGAÇÃO}

Fazer uso de uma água de boa qualidade está entre os fatores mais importantes para garantir que a irrigação atinja um potencial de funcionamento elevado. Dessa forma, avaliação da qualidade do uso da irrigação na agricultura precisa estar baseada na garantia do respeito aos princípios da sustentabilidade que busca conciliar o desenvolvimento econômico com a preservação ambiental e, ainda, ao combate da pobreza e das desigualdades sociais de acordo com (TESTEZLAF, 2017).

Os componentes presentes na água advém do ambiente natural ou introduzidos por ação antrópica, de acordo com Giacometti e Dominschek, (2018) os impactos ambientais agropastoris, principal setor da agricultura em que ocorreu o desmatamento, a utilização de agrotóxicos e fertilizantes que contaminam solos e águas subterrâneas devido ao uso discriminado desse produtos e além de muitas vezes a má utilização do solo que causa a desertificação. Dessa maneira, essa qualidade com exatidão a nível de irrigação dificilmente é alcançada, uma alternativa para interpretação eficiente é analisar os parâmetros que relaciona a água com seus efeitos no solo, na cultura e no manejo da irrigação, onde há seis parâmetros básicos que contém características para determinar a qualidade da água, são eles:

1) Salinidade, onde a concentração total de sais solúveis presente na água de irrigação é responsável por aumentar a salinidade do solo e ocasionar um decréscimo no potencial osmótico, afetando a disponibilidade de água no solo para a cultura;

2) Concentração de elementos tóxicos, o cloro e o sódio são os principais íons e mais presentes na água de irrigação causadores de problemas por toxidade;

3) Proporção relativa de sódio, em relação a outros cátions ou capacidade de infiltração no solo, esse parâmetro auxilia na determinação e eficiência na aplicação da lâmina de irrigação;

4) Concentração de bicarbonatos, águas com elevadas concentrações de íons de bicabornato podem ter precipitação de cálcio e magnésio na solução do solo;

5) Aspecto sanitário, devido ao fato da contaminação da água a ser utilizada para a irrigação contendo agentes patogênicos;

6) Aspecto de entupimento de emissores, esse parâmetro é mais comum e está relacionado com a irrigação localizada.

A adequabilidade da água é outro fator que depende da finalidade de uso, pois uma mesma água com determinada qualidade pode ser classificada como adequada para certo tipo de cultura e solo, e inadequada para outros, requerendo distintas variáveis de indicadores de qualidade da água. Logo, para avaliar as condições propícias para uso ou não de uma água para fins de irrigação deve-se analisar o conjunto dos parâmetros físicos, químicos e biológicos. As determinações mais usais são: a) indicadores físicos relacionados a cor, turbidez, temperatura, sólidos, b) indicadores químicos referentes ao $\mathrm{pH}$, alcalinidade, e diversos nutrientes como ferro, magnésio, fosforo, sulfatos etc, e c) indicadores biológicos englobando 
todos os organismos vivos presentes na linha lateral de irrigação, tais como algas, bactérias, protozoários, etc (GIACOMETTI; DOMINSCHEK, (2018).

\section{SISTEMA DE IRRIGAÇÃO LOCALIZADA}

De grande importância para o cenário agrícola, o sistema de irrigação localizada tem ganhado destaque devido ao método de funcionamento com ótima eficiência de aplicação através de pequena vazão e alta frequência e se bem instalada e projetada de forma adequada, apresenta uma uniformidade de aplicação acima de $90 \%$. Analisando o parâmetro ambiental tal eficiência torna a irrigação localizada a mais sustentável quando comparada com os outros métodos. Segundo Testezlaf (2017), na irrigação por gotejamento, por exemplo, aplica-se pequenos volumes de água, e com alta frequência (reduzido intervalo entre irrigações ou turno de rega), nas áreas localizadas na zona radicular das plantas, reduzindo as perdas e apresentando maiores valores de eficiência de aplicação quando comparada aos sistemas de aspersão e superfície.

A irrigação localizada tem por finalidade manter ótimos índices de umidade no solo nas áreas próximo ao sistema radicular da cultura, esse procedimento é garantido devido a estrutura ser conduzida por meio de tubulações sob baixa pressão, e disponibilizada através de emissores nas regiões onde se concentram as raízes da planta (BISCARO, 2016). Os emissores são os acessórios mais importantes do sistema, pois a modelagem permite diminuir o diâmetro da tubulação proporcionando baixa vazão da água, os modelos disponíveis no mercado de maior utilização pelos produtores são os gotejadores (comum, vazão regulável e de múltiplas saídas), mangueiras gotejadoras, microtubos, mangueiras exudantes, difusores e microaspersores (BISCARO, 2016).

Os emissores do tipo gotejador podem ser conectados no prolongamento da linha lateral, sobre a linha e dentro da linha. Os denominados autocompensantes são mais seguros em manter a vazão independente da pressão, devido a uma peça móvel e flexível que se desfigura sob pressão reduzindo o canal de passagem da água restringindo a vazão (PACHICO, 2014). Entretanto, essa mesma modelagem dos emissores que caracterizam a irrigação localizada, com um pequeno diâmetro do orifício de injeção de água, principalmente dos gotejadores são facilmente preenchidos por partículas, onde adquirem uma elevada susceptibilidade ao entupimento, sendo um dos problemas mais comuns e mais graves dentro desse sistema de irrigação (CRUZ, 2016), e que interfere na uniformidade de aplicação, juntamente com outros fatores na seguinte ordem: coeficiente de variação de fabricação, expoente de descarga do emissor, sensibilidade do emissor à temperatura, variações de pressão.

\section{FATORES QUE CONTRIBUEM PARA O ENTUPIMENTO DE GOTEJADORES}

$O$ impedimento da passagem da água, ou diminuição da frequência $e$ intensidade que esta percorre nos emissores por ventura do fenômeno de entupimento compromete a vida útil do sistema de irrigação, e, dessa forma, o componente emissor do sistema deve ser recuperado ou mesmo substituído (BISCARO et al., 2016). Tendo em vista esses fatos, Biscaro et al. (2016) salientam a importância do conhecimento das propriedades da água, bem como a origem, para que se possa determinar a escolha do método de irrigação.

De acordo com Silva et al., (2015) com a vazão dos emissores utilizados para irrigação por gotejamento na cultura da cana-de-açúcar se mantém dentro do controle estatístico de qualidade e com alto padrão de uniformidade de distribuição e 
eficiência desde que sejam realizadas os serviços de manutenção e um bom manejo de irrigação.

\section{ENTUPIMENTO FÍSICO}

As partículas físicas de potencial causadoras de entupimento são de origem orgânicas tais como fragmentos de pequenos animais, algas, ovos de larvas, aglomerado de bactérias, e de origem inorgânica relacionados a partículas de solo (areia, silte e argila) e restos plásticos. Esses componentes quando presentes na água e arrastados até os orifícios dos emissores onde causam entupimento provocando insuficiência na vazão, podendo até mesmo obstruir as linhas laterais da tubulação comprometendo a eficiência do sistema o que ocasiona uma irrigação com desuniformidade (SILVA et al., 2012).

A obstrução ocasionada por partículas sólidas pode ocorrer por meio de duas modalidades, sendo a obstrução total quando o orifício do emissor apresenta uma seção de passagem menor do que a partícula, e a obstrução por partículas finas que vão se acumulando gradualmente na tubulação. Os sistemas de irrigação apresentam uma elevada variação na intensidade de obstrução, que depende do tamanho e concentração das partículas, velocidade de escoamento da água na linha lateral e a combinação entre eles. (PERBONI, 2016).

Alves et al. (2015) constataram em experimento a ocorrência do entupimento físico, no sistema de irrigação com microtubos, que a deposição de areia se concentrou nas entradas dos emissores e conectores, locais onde a velocidade da água eram próximas ou igual a zero, concluindo que o risco de entupimento por sedimentação e acumulação dos materiais é maior de acordo com que a velocidade da água diminui, concordando assim com os relatos de Coelho et al. (2007) sobre a influência da velocidade da água no processo de obstrução.

\section{ENTUPIMENTO QUÍMICO}

O entupimento físico é o tipo de entupimento mais difícil de localizar e identificar, quando em estágios avançados o tratamento se torna dificultoso. As principais causas desse entupimento geralmente resultam pelo excesso de carbonato de cálcio, magnésio, pela oxidação de ferro, entre outros, elementos, de acordo com Carvalho et al., (2014) esse material forma incrustações que podem bloquear, parcial ou completamente a passagem da água.

O ferro e o manganês quando ao natural apresentam características solúveis, porém ao entrar em contato com a água ou com o oxigênio atmosférico são oxidados de tal maneira que se precipitam nas linhas laterais da tubulação ocasionando o entupimento. (BUSATO et al., 2012). Já o carbonato e sulfeto de cálcio sob altas concentrações formam incrustações tanto nas paredes da tubulação quanto nos emissores, quando as águas subterrâneas são utilizadas para a irrigação, os problemas com encrostamento são mais frequentes.

Devido a fenômenos de precipitação de íons a obstrução ocorre com maior probabilidade por motivos de interação de elevadas temperaturas da água de acordo com Ribeiro et al., (2005). Por outro lado, Mesquita (2016) comenta que dependendo da região, os principais precipitados que aumentam o risco de entupimento de sistemas de irrigação por gotejamentos em regiões áridas e semiáridas são os seguintes elementos: cloretos, nitrato de cálcio, sulfato de cálcio, hidróxido de manganês, fosfato de ferro, carbonato de cálcio e bicarbonato. 


\section{ENTUPIMENTO BIOLÓGICO}

Os agentes centrais causadores de obstrução biológica dos emissores são geralmente algas, zooplânctos e mucilagem bacteriana. Águas utilizadas na irrigação localizada, apresentam diversos fatores para a ocorrência de bactérias e algas, tais como o frequente uso de fertirrigação, água de reservatórios ou canais, e faixas de temperaturas ótimas para o desenvolvimento microbiano (BATISTA et al., 2010).

Quando se utiliza para a irrigação efluente de esgoto, segundo LI et al., (2013) o entupimento biológico dos emissores causados pelo acúmulo de biofilme na tubulação é um dos mais graves problemas associados com os sistemas de irrigação por gotejamento. O biofilme de acordo com Noronha (2013) é a interação de microrganismos que adquirem comportamento distinto quando em formas livres, sendo essa uma associação complexa.

Existe ainda, a possibilidade do ferro desencadear a obstrução biológica, pois as ferrobactérias são estimuladas pelo elemento ferro a produzem mucilagem formando crosta de ferrugem no interior das tubulações. Essas ferrobactérias atuam aproveitando a energia resultante no processo de conversão do óxido ferroso em hidróxido férrico, originando um composto que é depositado em forma de bainhas sobre os microrganismos. Os gêneros mais comuns causadores de problemas são Sphaerotillus, Leptothrix, Crenothrix e Gallionella (BUSATO; SOARES, 2010).

\section{MEDIDAS DE CONTROLE}

A prevenção é a medida mais economicamente viável, desde que tomada no início de instalação do projeto e para maximizar a eficiência do sistema de irrigação é necessário avaliar o desempenho hidráulico, a uniformidade de distribuição de água pelos emissores e realizar ajustes necessários na operação e no manejo conforme Caitano et al., (2011). Garantir a eficiência da irrigação está interligado com os sistemas utilizados para solucionar o problema de obstrução, dentre os mecanismos disponíveis para o tratamento de água contra o entupimento encontrase os oriundos de processos físicos que utiliza como principal fonte a filtração e o tratamento químico, sendo a fonte mais utilizada o uso da água clorada (RIBEIRO et al., 2004).

A filtragem é uma alternativa como medida preventiva, consiste no conjunto de tratamentos ou funções que realizam a retirada de partículas indesejadas da água. A adoção de alguns filtros selecionados permite o tratamento da água e o funcionamento do sistema de irrigação localizada, são vários os modelos de sistemas compreendendo filtros de areia, de tela, disco ou de anel, tela plástica ou de aço inoxidável, e os pré-filtros sendo os separadores centrífugos (hidrociclones) e decantadores, indicados para tratamento de água que contenha alto teor de sólidos suspensos, instalados antes do cabeçal de controle (RIBEIRO et al., 2004).

Outra medida de tratamento químico é o uso de cloros. O cloro em caráter comercial pode ser encontrado apresentando duas formas distintas de origem, sendo inorgânica e orgânica, a primeira se apresenta na forma gasosa tal como o gás cloro e na forma sólida sendo o hipoclorito de sódio e de cálcio, já o de origem orgânica pode ser encontrado na forma de pó ou granulado com a denominação de dicloroisocianurato de sódio e ácido tricloroisocianúrico. Foi utilizado o produto comercial MaxBio cloro orgânico como fonte de tratamento e obtidos ótimos resultados (COSTA, 2014) e, com o tratamento com cloro inorgânico os autores Busato et al., (2012) comprovaram sua eficácia na desobstrução de tubulações. 
A posição da linha de irrigação é um fator que poderá contribuir para susceptibilidade dos gotejadores à obstrução, pois pode ocorrer um efeito de decantação de partículas durante a passagem do fluxo de água, ou mesmo a granulometria desse material influenciando na obstrução (AMARAL, 2017)

Carvalho et al., (2016) em estudo quantificaram possíveis distúrbios de vazão e avaliaram gotejadores ao entupimento por ferro solúvel na água de irrigação e concluíram que emissores posicionados para baixo e para cima. Os emissores que estão em posicionamento para baixo dos orifícios foram os que mais demonstraram suscetibilidade ao entupimento.

A obstrução de gotejadores altera a vazão e consequentemente diminui a uniformidade da aplicação, dessa forma Silva et al., (2014), ao trabalharem com unidades gotejadoras aplicando água residuária tratada sob pressões de serviço, observaram que após $160 \mathrm{~h}$ de operação não é recomendado o uso de gotejadores de baixa vazão nominal $\left(\leq 1,6 \mathrm{I} \mathrm{h}^{-1}\right)$ e maior comprimento de labirinto ( $\left.\geq 58 \mathrm{~mm}\right)$. Por outro lado, Morata et al., (2014), obtiveram resultados contrastantes, pois não foi notado efeito significativo do tempo de operação na redução da vazão dos gotejadores, após 320 h de aplicação de esgoto doméstico. Já Oliver et al., (2014) obtiveram reduções nos valores de coeficiente de vazão relativa média de até $53 \%$, após $3600 \mathrm{~h}$ de operação dos sistemas de irrigação por gotejamento.

\section{CONSIDERAÇÕES FINAIS}

Revisar e reunir diversas experiências sobre o tema facilita a busca do leitor pelo tema, e auxilia na tomada de decisão uma vez que os produtores possam ter relatos experimentais em circunstâncias próximas da realidade de seus problemas com a obstrução. A pesquisa possibilitou observar o quanto a irrigação vem sendo utilizada, tornando-se imprescindível para garantir uma agricultura de sucesso e o quão é importante para o bom funcionamento do sistema que se realize a manutenção dos componentes e conheça as características da água utilizada para a irrigação.

A revisão literária acerca das causas e possíveis tratamentos da obstrução de emissores no sistema de irrigação localizada realizada nessa pesquisa adquiriu resultados relativamente satisfatórios, alcançando 22 experimentos específicos sobre o tema foi possível realizar uma revisão bibliográfica bastante abrangente sobre o assunto, porém devido o enfoque da temática ser de extrema importância, o número de trabalhos referentes a contextualização do tema conclui-se que no geral os tratamentos ainda são utilizados de forma precária, uma vez que os problemas com entupimentos ainda acontecem de forma intensa se tornando uma realidade no cotidiano do produtor rural.

Autores que realizaram alguma pesquisa sobre o tema dificilmente aderem a continuidade de novas investigações sobre o assunto. Juntamente com o baixo número de pesquisas por ano, tornam-se fatores concretos sobre a necessidade de ser abordado na literatura novos trabalhos que apresentem alguma metodologia de tratamento com resultados positivos ou negativos acerca da desobstrução de componentes emissores, para que o acervo de informações seja grandiosamente vasto.

Quanto ao resultado da pesquisa, foi possível verificar a grande interação dos agentes obstrutores atuando em uma mesma unidade de irrigação. Assim como investigou-se os relatos dessas interações, houve casos de pesquisas em que 0 estudo teve um direcionamento apenas para uma natureza obstrutora, e o que obteve menor frequência de relatos foi a obstrução de caráter biológico. A 
importância da pesquisa gira em torno também dos possíveis tratamentos que os interessados sobre o tema (irrigantes) possam vir a fazer uso. O tratamento clorado foi o mais utilizado dentre os demais, sendo empregado para diversas causas obstrutoras, seguido dos ácidos e filtros.

Diante do cenário pesquisado recomenda-se que novas pesquisas sejam realizadas a campo reproduzindo as necessidades cotidianas dos irrigantes, atendendo os grandes e pequenos produtores, e outros levantamentos caracterizando a qualidade das águas que estão sendo utilizadas para irrigação na região Centro Oeste.

\section{REFERÊNCIAS}

Agência Nacional de Águas. Relatório da ANA apresenta situação das águas do Brasil no contexto de crise hídrica. 2017. Disponível em: <http://www3.ana.gov.br/portal/ANA/noticias/relatorio-da-ana-apresenta-situacaodas-aguas-do-brasil-no-contexto-de-crise-hidrica>. Acesso em: 11 abr. 2019. Agência Nacional de Águas. Atlas Irrigação: uso da água na agricultura irrigada, Brasilia: ANA, p.86, 2017.

ALVES, D. G.; PINTO, M. F.; MOLLE, B.; TOMAS, S.; MOUHEB, N. A.; BROTEL,T. A. Sensibilidade dos microtubos à obstrução por agentes físicos. Revista Brasileira de Agricultura Irrigada, Fortaleza, v.9, n.4, p. 193-203, 2015. DOI: 10.7127/rbai.v9n400310. ISSN 1982-7679 (On-line).

AMARAL, M.A.C.M.; Efeito do pulso de partículas sólidas na obstrução de tubogotejadores. Tese de Doutorado, Escola Superior de Agricultura "Luiz de Queiroz" - USP, Piracicaba- SP, 2017, 66p. Disponível em: < https://www.teses.usp.br/teses/disponiveis/11/11152/tde-16032018-

095657/publico/Marcos_Antonio_Correa_Matos_do_Amaral_versao_revisada.pdf> Acesso em: 28 abr. 2020.

BATISTA, R. O.; FIA, R; SILVA, D. F. Qualidade das águas residuárias para irrigação. Lavras: ed. UFLA, Boletim Técnico n. 99, P. 1-31, 2014.

BISCARO, G. A. Irrigação localizada: Aspectos gerais. In: BISCARO, G. A. Sistema de irrigação localizada. Dourados: Universidade Federal da Grande Dourados, 2016. cap. 1. ISBN: 978-85-8147-085-6.

BUSATO, C. C. M.; SOARES, A. A. Desempenho de gotejadores utilizando água de baixa qualidade química e biológica. Bioscience. Journal, Uberlândia, v.26, n.5, p.739-746,2010. Disponível em: http://www.seer.ufu.br/index.php/biosciencejournal/article/view/7174. Acesso em: 18 out. 2019.

BUSATO, C. C. M.; SOARES, A. A.; RAMOS, M. M.; REIS, E. F.; BUSATO, C.Dicloroisocianurato na prevenção do entupimento devido ao uso de águas ferruginosas em sistemas de irrigação por gotejamento. Semina: Ciências Agrárias, Londrina, v.33, n.1, p. 49-56, 2012 DOl:10.5433/16790359.2012v33n1p49. Corpus ID: 83548583. 
CAITANO, R.F; LOPES, F.B.; SOUZA, F.; MENDONÇA, M.A.B. Desempenho dos sistemas de irrigação na cultura da banana no perímetro irrigado baixo Acaraú, Ceará. Revista Brasileira de Agricultura Irrigada, v.5, p.113-122,2011. DOI: 10.7127/rbai.v5n200051.

CARDOSO, B. F.; OYAMADA, G. C.; SILVA, C. M. Produção, tratamento e uso de dejetos suínos no Brasil. Desenvolvimento em questão, v.13, n.32, p.127-145, 2015. Disponível em: http://www.spell.org.br/documentos/ver/37872/producao--tratamentoe-uso-dos-dejetos-suinos-no-brasil-/i/pt-br. Acesso em: 12 mai. 2020.

CARVALHO, L. C. C.; COELHO, R. D.; TEIXEIRA, M. B.; CUNHA, F. N.; SILVA,N. F. Gotejadores submetidos a aplicação de ferro solúvel. Revista Brasileira de Agricultura Irrigada, Fortaleza, v.8, №.6, p. 528-537, 2014. DOI: 10.7127/RBAI.V8N600264.

CARVALHO, L.C.C.; COELHO, R.D; TEIXEIRA, M.B.;CUNHA, F.N.;SILVA; SOARES, F.A.L.;VIDAL, V.M.; MORAIS, W. A.Entupimento de emissores autocompensantes com aplicação de sulfato e óxido de ferro. Revista Cientifica, Jaboticabal v.44, n.3, p.385-402, 2016 ISSN: 1984-5529 http://dx.doi.org/10.15361/1984-5529.2016v44n3p385-402.

COELHO, R. D.; VILELA, L. A. A.; REZENDE, R. S.; TEIXEIRA, M. B.; SÁ, J. S. Entupimento de gotejadores em decorrência de pulsos de partículas sólidas na malha hidráulica. Irriga, Botucatu, v.12, n.1, p.108-122, 2007. DOI: 10.15809/irriga.2007v12n1p108-122.

COELHO, E. F.; SILVA, A. J. P.; PARIZOTTO, I.; SILVA, T. S. M. Sistemas e manejo de irrigação de baixo custo para agricultura familiar. Cruz das Almas: Embrapa Mandioca e Fruticultura, p. 45, 2017. Disponível em< https://ainfo.cnptia.embrapa.br/digital/bitstream/item/133043/1/Cartilha-ManejoIrrigacao-03-09-2015.pdf. Acesso em: 10 abr. 2020.

COSTA, D. O. Eficácia do tratamento biológico em gotejadores operando com água residuária domestica tratada. Dissertação de Mestrado. Universidade Federal Rural do Semi-Árido, Mossoró, 2014. 110 p. Disponível em: < https://ppgmsa.ufersa.edu.br/wpcontent/uploads/sites/59/2014/10/DISSERTA\%C3\%87\%C3\%83O-Danniely-deOliveira-Costa.pdf>. Acesso em: 12 abr.2020.

CRUZ, R. L. Qualidade da Água. In: BISCARO, G. A. Sistema de irrigação localizada. Dourados: Universidade Federal da Grande Dourados, cap.5, 2016.

FUNDAÇÃO GETÙLIO VARGAS (FGV): Estudo sobre eficiência do uso da água no Brasil: Análise de impacto da irrigação na agricultura brasileira e potencial de produção de alimentos face ao aquecimento global.p.28, São Paulo,2016. Disponivel em: <https://bibliotecadigital.fgv.br/dspace/handle/10438/17675>. Acesso em: 10 mar. 2020.

FREITAS C. A. S.; NASCIMENTO J. A. M.; BEZERRA F. M. L.; LIMA R. M. M. Use of treated sewage as water and a nutritional source for bean crops. Revista Caatinga. Mossoró, v. 31, n. 2, p 487-494, abr.-jun., 2018. SSN 0100-316X 
(impresso)ISSN1983-2125 (online). Disponível em: <https: periódicos.ufersa.edu.br/index.php/caatinga>. Acesso em: 02 abr. 2020.

GIACOMETTI, K.; DOMINSCHEK, D. L. AÇÕES ANTRÓPICAS E IMPACTOS AMBIENTAIS:INDUSTRIALIZAÇÃO E GLOBALIZAÇÃO. Caderno Intersaberes - v. 7 n. $\quad 10 \quad-\quad 2018 . \quad 20$ Disponível https://www.uninter.com/cadernosuninter/index.php/intersaberes/article/download/10 78/878.> Acesso em: 10 abr. 2020.

IGBE - Instituto Brasileiro de Geografia e Estatística . Censo Agropecuário 2017, Rio de janeiro.

LIMA,M.G.M.; FERREIRA, D.J.L.; GOMES, A.H.S.; NETO, J.D. Entupimento de mangueira gotejadora após exposição à água salina. Congresso Técnico Científico da Engenharia e da Agronomia CONTECC'2018 - Maceió - AL, 2018.Anais... Macéio. Disponivel em: <www.scholar.google.com/confea.com.br>. Acesso em: 03 abr. 2020.

LI Y, ZHOU B, LIU Y, JIANG Y, PEI Y, SHI Z. Preliminary surface topographical characteristics of biofilms attached on drip irrigation emitters using reclaimed water. Irrigation Science, v. 31, 557-574. 2013. http://dx.doi.org/10.1007/s00271-0120329-1 - ISSN:0342-7188.

MAIA, V. Informações importantes para irrigação por gotejamento, 2018. Irrigação e Drenagem. Disponível em: <http://www.portaldomeioambiente.com.br/irrigacao-porgotejamento>. Acesso em: 24 out. 2019.

MESQUITA, F. O. Desempenho de gotejadores e produção de capim elefante (Pennisetum purpureum schum.) com percolado de aterro sanitário no semiárido. 2016. 149f. Tese de Doutorado - Universidade Federal Rural do SemiÁrido, Mossoró, RN. Disponível em: <https://ppgmsa.ufersa.edu.br/wpcontent/uploads/sites/59/2015/04/Tese-Francisco-de-Oliveira-Mesquita.pdf>. Acesso em: 24 out. 2019.

MORATA, G. T.; DANTAS, G. F.; DALRI, A. B.; PALARETTI, L. F.; FARIA, R. T.; SANTOS, G. O.Entupimento de gotejadores com uso de efluente de esgoto sob dois sistemas de filtragem.Revista Brasileira de Agricultura Irrigada, v. 8, p. 86 - 97, 2014. DOI: 10.7127/RBAI.V8N200227.

NORONHA, C. R. S. Dinâmica de obstrução de gotejadores em sistema de fertirrigação operando com águas residuárias domésticas e a ação de bactérias na desobstrução. Tese de Doutorado. Universidade Federal de Viçosa, $\begin{array}{llllll}V & 2013 . & 72 & \text { p. } & \text { Disponível } & \text { em:< }\end{array}$ http://www.locus.ufv.br/handle/123456789/10451>.Acesso em: 22 nov.2019.

OLIVER, M. M. H.; HEWA, G. A.; PEZZANITI, D. Bio-fouling of subsurface type drip emitters applying reclaimed water under medium soil thermal variation. Agricultural Water Management, v. 133, p. 12-23, 2014. DOI: 10.1016/j.agwat.2013.10.014.

PACHICO, I. W. L. Avaliação de sistema de irrigação localizada de baixo custo recomendado a pequenos agricultores da região semiárida. Dissertação de ENCICLOPÉDIA BIOSFERA, Centro Científico Conhecer - Goiânia, v.17 n.32; p. 212 
Mestrado. Universidade Federal Rural do Semi-Árido, Mossoró, 2014. 67 p. Disponível

em:< https://repositorio.ufersa.edu.br/bitstream/tede/490/1/ltaloWLPDISSERT.pdf $>$ Acesso em: 12 out. 2019.

PERBONI, A. Sensibilidade de gotejadores à obstrução por partículas de areia. Tese de Doutorado. Escola Superior de Agricultura Luiz de Queiroz, Piracicaba, 2016. 71p. Disponível em: <http://www.teses.usp.br/teses/disponiveis/11/11152/tde19042016-103353/publico/Acacio_Perboni_versao_revisada.pdf>.Acesso em:03 mai. 2020.

RIBEIRO, T. A. P.; PATERNIANI, J. E. S.; AIROLDI R. P. S.; SILVA, M. J. M. O efeito da qualidade da água no entupimento de emissores e no desempenho de filtros utilizados na irrigação por gotejamento. Irriga, Botucatu, v.9, n.2, p. 136-149, 2004. DOI: https://doi.org/10.15809/irriga.2004v9n2p136-149.

RIBEIRO, T. A. P.; AIROLDI, R. P. S.; PATERNIANI, J. E. S.; SILVA, M. J. M. Variação dos parâmetros físicos, químicos e biológicos da água em um sistema de irrigação localizada. Revista Brasileira de Engenharia Agrícola e Ambiental, Campina Grande, v.9, n.3, p. 295-301, 2005. Disponível em: http://www.agriambi.com.br. Acesso em: 4 nov. 2019.

SILVA, L. P.; SILVA, M. M.; CORREA, M. M.; SOUZA, F. C. D.; SILVA, E. F. F. Desempenho de gotejadores autocompensantes com diferentes efluentes de esgoto doméstico. Revista Brasileira de Engenharia Agrícola e Ambiental v.16, n.5, p.480-486, 2012. Campina Grande, PB. ISSN 1415-4366. http://dx.doi.org/10.1590/S1415-43662012000500003.

SILVA, K. B.; SILVA JÚNIOR, M. J.; BATISTA, R. O.; SANTOS, D. B.; LEMOS FILHO, L.C. A. Irrigação por gotejamento com água residuária tratada da indústria da castanha de caju sob pressões de serviço. Semina: Ciências Agrárias, v. 35, p. 695-706, 2014. DOI: 10.5433/1679-0359.2014v35n2p695.

SILVA, S.; NETO, J.D.TEODORO, I.; SANTOS, M.A.L.;BRUNO, ANDRADE,A.B.A.; CORDÃO, M.A. Qualidade da irrigação por gotejamento em cultivos consecutivos de cana-de-açúcar. Agropecuária Científica no Semiárido - V. 11, n. 2, p. 01-08, 2015. ISSN 1808-6845.Disponivel em: <http:150.165.111.246/ojspatos/index.php/ACSA>. Acesso em: 10 nov. 2019.

TESTEZLAF. R Irrigação: métodos, sistemas e aplicações. Universidade Estadual de Campinas -- Campinas, SP.Unicamp/FEAGRI, 2017, 215p.Disponivel em: < http://www.bibliotecadigital.unicamp.br/document/?down=74329>. Acesso em: 05 mai. 2020.

ZOCOLER, J. L.; RIBEIRO, P. H. P.; Silva, N. F.; CUNHA, F. N.; TEIXEIRA, M. B.; SOARES, F. A. L. Desempenho de um sistema de irrigação por gotejamento com aplicação de água salina. Irriga, Botucatu, Edição Especial, p. 234-247, 2015. ISSN 1808-3765. DOI: https://doi.org/10.15809/irriga.2015v1n1p234. 